\title{
Catalysis of olefin oligomerization by Ni(I) complexes
}

\author{
Vitaliy V. Saraev, ${ }^{\text {a,* Petr B. Kraikivskii, }}{ }^{a}$ Vadim V. Annenkov, ${ }^{b}$ Stanislav N. Zelinskiy, \\ Dmitriy A. Matveev, ${ }^{a}$ Aleksey I. Vilms, ${ }^{a}$ Elena N. Danilovtseva, ${ }^{b}$ and Koop Lammertsma ${ }^{c}$ \\ ${ }^{a}$ Irkutsk State University, Irkutsk, Russia \\ ${ }^{b}$ Limnological Institute Siberian Branch of Russian Academy of Sciences, Irkutsk, Russia \\ ${ }^{c}$ Vrije Universiteit, Amsterdam, the Netherlands \\ E-mail:saraev@admin.isu.ru
}

(received 04 Jul 05; accepted 27 Aug 05; published on the web 31 Aug 05)

\begin{abstract}
Activity of nickel-complex catalysts is traditionally attributed with hydride Ni(II) complexes generated by oxidation of $\mathrm{Ni}(0)$ particles with Brønsted acids. In this work catalytic activity of $\mathrm{Ni}(\mathrm{I})$ complexes obtained in the system $\mathrm{Ni}\left(\mathrm{PPh}_{3}\right)_{4} / \mathrm{BF}_{3} \cdot \mathrm{OEt}_{2}$ have been studied. On the basis of EPR and ${ }^{1} \mathrm{H}$ NMR data, the formation of dimeric catalytic complexes with ethylene and styrene has been found. Ethylene transformation on $\mathrm{Ni}(\mathrm{I})$ catalyst results in 1-butene, 2-butene and trimers mixture. In the case of styrene, the polymers with molecular mass 2500 were obtained. These polymers contain terminal double bonds which can be used in design of new graft copolymers.
\end{abstract}

Keywords: Catalysis, ethylene, styrene, oligomerization, nickel, complex

\section{Introduction}

Complexes of transition metals become more and more widespread as catalysts of hydrocarbon reactions ${ }^{1,2}$ and they successfully compete with more expensive systems based on noble metals. The activity of nickel-complex catalysts in oligo- and polymerization of unsaturated hydrocarbons opens routines to new polymers, valuable reagents and products of organic synthesis. ${ }^{3-10}$ Unfortunately, there is only limited data concerning with the nature of these catalysts, the structure of the active center and the reaction mechanism. Such a situation is connected with the complexity and multi-component composition of the usually used nickel catalysts. At the same time, relatively simple catalytic systems from triphenylphosphinic nickel complexes allow to carry out oligomerization and to obtain reliable information about mechanism of the reaction. ${ }^{11}$

The activity of the nickel-complex catalysts is traditionally attributed to the hydride Ni(II) complexes generated by the oxidation of $\mathrm{Ni}(0)$ particles with Brønsted acids such as $\mathrm{ROH}$, 
$\mathrm{CF}_{3} \mathrm{COOH}, \mathrm{HBF}_{3} \mathrm{OR} .^{11-14}$ On the other hand, it was shown earlier ${ }^{15}$ that the phosphinic complex $\mathrm{Ni}\left(\mathrm{PPh}_{3}\right)_{4}$ can be oxidized by boron trifluoride giving rise to $\left[\mathrm{Ni}\left(\mathrm{PPh}_{3}\right)_{3}\right] \mathrm{BF}_{4}$ which has been confirmed by a typical $\mathrm{Ni}(\mathrm{I})$ signal in EPR spectrum. Elimination of phosphorus-containing ligands is possible in the excess of $\mathrm{BF}_{3} \cdot \mathrm{OEt}_{2}$ and the resulting coordinating-unsaturated $\mathrm{Ni}(\mathrm{I})$ complexes are able to catalyse oligomerization of ethylene and propylene. This work is devoted to the study of triphenylphosphinic nickel(I) complexes as catalysts in ethylene and styrene oligomerization and to the clarification of the active center structure.

\section{Results and Discussion}

Quantitative oxidation of $\mathrm{Ni}(0)$ to $\mathrm{Ni}(\mathrm{I})$ in the catalytic system $\mathrm{Ni}\left(\mathrm{PPh}_{3}\right)_{4} / \mathrm{BF}_{3} \cdot \mathrm{OEt}_{2}$ gives rise to three cationic $\mathrm{Ni}(\mathrm{I})$ complexes: $\left[\mathrm{Ni}\left(\mathrm{PPh}_{3}\right)_{3}\right] \mathrm{BF}_{4},\left[\left(\mathrm{PPh}_{3}\right)_{2} \mathrm{Ni}\left(\mathrm{OEt}_{2}\right)\right] \mathrm{BF}_{4}$ and $\left[\left(\mathrm{PPh}_{3}\right) \mathrm{Ni}\left(\mathrm{OEt}_{2}\right)_{2}\right] \mathrm{BF}_{4}$ which ratio depends on concentration of the Lewis acid [16]. Maximum concentration of cationic complex $\left[\left(\mathrm{PPh}_{3}\right)_{3} \mathrm{Ni}\right] \mathrm{BF}_{4}$ was found at molar ratio $\mathrm{B}: \mathrm{Ni}=4$ and this complex exists in double degenerated basic state in toluene solution ${ }^{16}$ which is seen as spread asymmetric signal 1 in EPR spectrum at $77 \mathrm{~K}$ due to Jahn-Teller effect (Figure 1). This complex is inactive relative to ethylene at atmospheric pressure and room temperature. Elimination of one triphenylphosphinic ligand from coordinating sphere of cationic complex $\left[\mathrm{Ni}\left(\mathrm{PPh}_{3}\right)_{3}\right] \mathrm{BF}_{4}$ by the action of $\mathrm{BF}_{3} \cdot \mathrm{OEt}_{2}$ results in $\left[\mathrm{Ni}\left(\mathrm{PPh}_{3}\right)_{2}\left(\mathrm{OEt}_{2}\right)\right] \mathrm{BF}_{4}$ complex (Figure 1, spectrum 2). The obtained solution absorbs ethylene due to oligomerization. This is accompanied with disappearance of EPR signal 2 from $\left[\mathrm{Ni}\left(\mathrm{PPh}_{3}\right)_{2}\left(\mathrm{OEt}_{2}\right)\right] \mathrm{BF}_{4}$ and appearance of time-unstable signal 3 (Figure 1) with hyperfine structure from one phosphorus nucleus.

Evidently, we have here substitution of phosphinic ligand and, probably, ether with ethylene giving rise in $\pi$-complex $\left[\left(\mathrm{PPh}_{3}\right) \mathrm{Ni}\left(\eta^{2}-\mathrm{C}_{2} \mathrm{H}_{4}\right)_{2}\right] \mathrm{BF}_{4}$. This complex is unstable and exists in solution for several second, after that EPR signal 3 disappears and is not visible during the whole reaction. Maximum activity of the catalyst falls at the first 40-80 seconds reaching 30000 ethylene (mol consumed) / $[\mathrm{Ni}(\mathrm{mol}) \cdot \mathrm{h}]$ at $\mathrm{B}: \mathrm{Ni}=80$, after that the reaction velocity slumps (Figure 2). The principal products of the reaction are butene-2 (60-65\%), butene-1 (25-30\%) and up to $10 \%$ of trimers (methylpentenes and $n$-hexenes). 


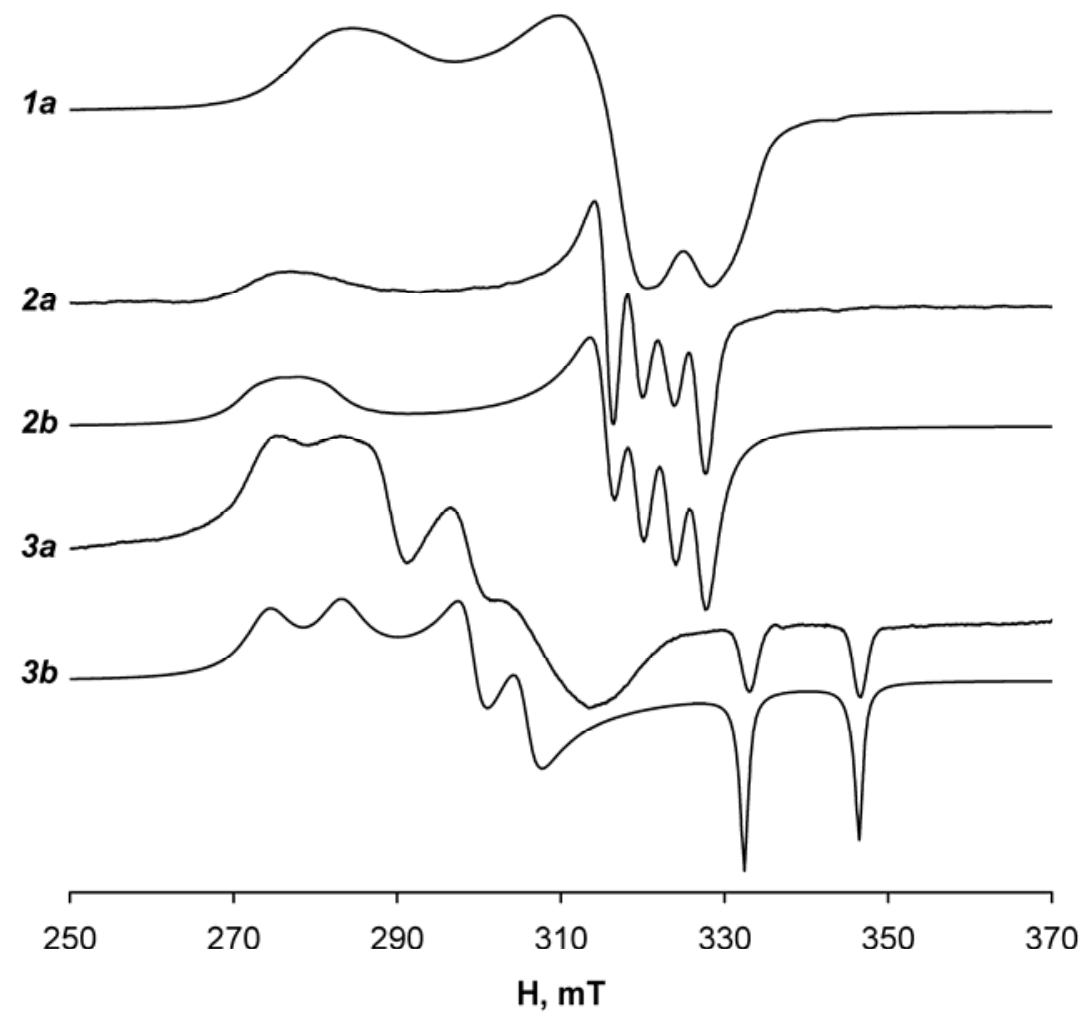

Figure 1. Experimental (a) and simulated (b) EPR spectra of the nickel(I) complexes: $\left[\mathrm{Ni}\left(\mathrm{PPh}_{3}\right)_{3}\right] \mathrm{BF}_{4}(1),\left[\left(\mathrm{PPh}_{3}\right)_{2} \mathrm{Ni}\left(\mathrm{P}(\mathrm{OEt})_{3}\right)_{2}\right] \mathrm{BF}_{4}(2)$ and $\left[\left(\mathrm{PPh}_{3}\right) \mathrm{Ni}\left(\eta^{2}-\mathrm{C}_{2} \mathrm{H}_{4}\right)_{2}\right] \mathrm{BF}_{4}(3)$ in toluene solution, $\mathrm{T}=77 \mathrm{~K}$.

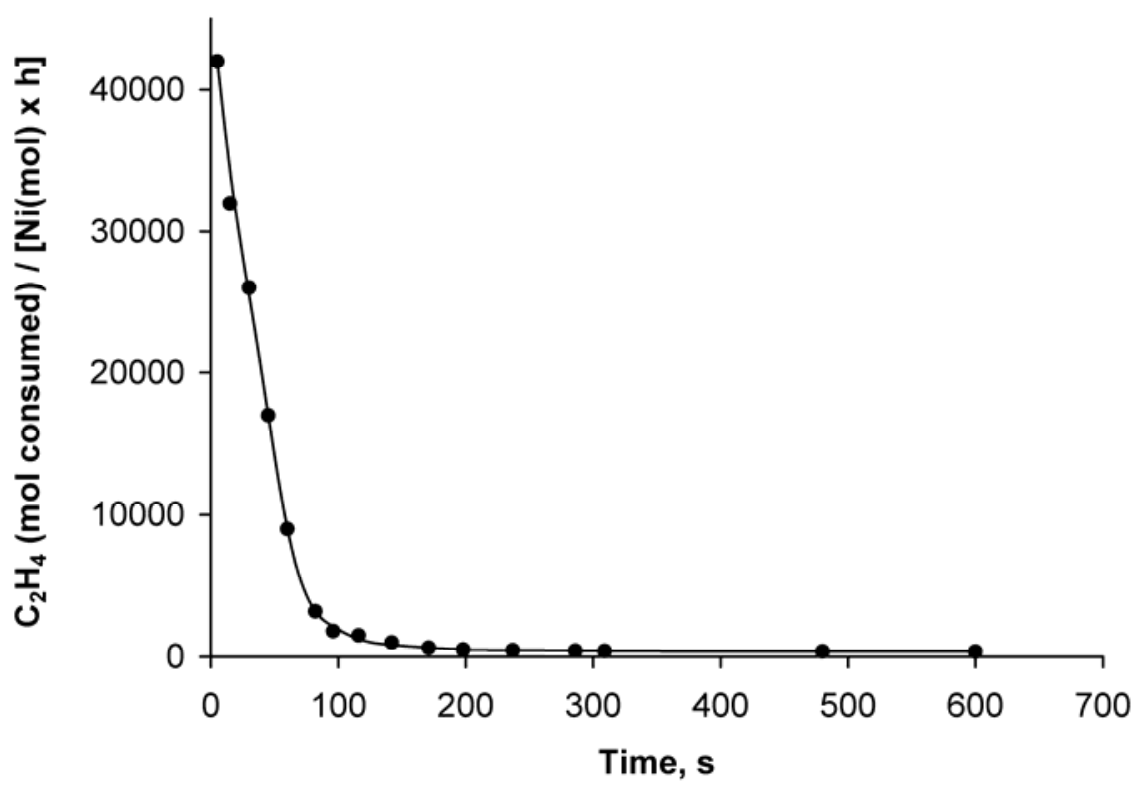

Figure 2. Time dependence of activity of $\mathrm{Ni}\left(\mathrm{PPh}_{3}\right)_{4} / \mathrm{BF}_{3} \cdot \mathrm{OEt}_{2}(\mathrm{~B}: \mathrm{Ni}=80)$ catalytic system in ethylene oligomerization. 
The disappearance of EPR signals in the beginning of the catalytic reaction can be attributed with a change of $\mathrm{Ni}(\mathrm{I})$ oxidation degree or with dimerization of these ions. On the other hand, addition of triethylphosphite (catalytic poison), to the reaction mixture stops the oligomerization immediately and an intensive EPR signal from Ni(I) appears. This spectrum corresponds to $\left[\left(\mathrm{PPh}_{3}\right) \mathrm{Ni}\left(\mathrm{P}(\mathrm{OEt})_{3}\right)_{3}\right] \mathrm{BF}_{4}$ complex. ${ }^{17}$ There is a straight-line relationship between the oligomerization velocity at the moment of triethylphosphite introduction and intensity of new EPR signal (Figure 3). Therefore, activity of the system is connected with cationic Ni(I) complexes which are present in the form of diamagnetic dimers during ethylene oligomerization. Termination of the reaction by triethylphosphite is accompanied by destruction of the dimers and release of the paramagnetic $\mathrm{Ni}(\mathrm{I})$ particles.

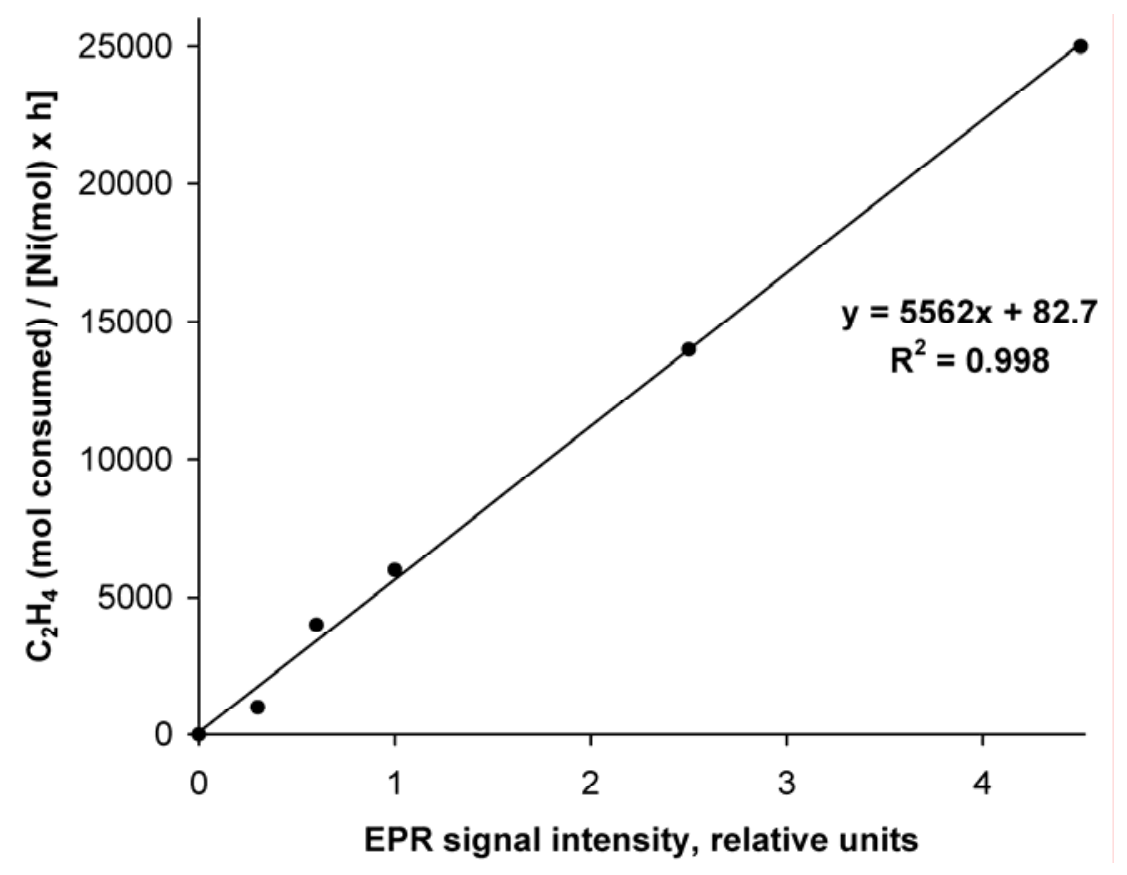

Figure 3. Catalytic activity of $\mathrm{Ni}\left(\mathrm{PPh}_{3}\right)_{4} / \mathrm{BF}_{3} \cdot \mathrm{OEt}_{2}(\mathrm{~B}: \mathrm{Ni}=80)$ system in ethylene oligomerization vs. Ni (I) concentration.

The detail study of the diamagnetic particles is experimentally complicated using gaseous substrate, so we have used styrene in this reaction. In contrast to ethylene, styrene reacts actively with the initial cationic complex $\left[\mathrm{Ni}\left(\mathrm{PPh}_{3}\right)_{3}\right] \mathrm{BF}_{4}$. For example, the addition of styrene (molar ratio styrene: $\mathrm{Ni}=2)$ to catalytic system $\mathrm{Ni}\left(\mathrm{PPh}_{3}\right)_{4} / \mathrm{BF}_{3} \cdot \mathrm{OEt}_{2}(\mathrm{~B}: \mathrm{Ni}=4)$ in which nickel is present as $\left[\mathrm{Ni}\left(\mathrm{PPh}_{3}\right)_{3}\right] \mathrm{BF}_{4}$ results in immediate disappearance of EPR signal from initial $\mathrm{Ni}(\mathrm{I})$ complex. At the same time, a set of signals in NMR ${ }^{13} \mathrm{C}$ was noted in the weak field $(156,140$, 136, 135 and $129 \mathrm{ppm}$, Figure 4) which is characteristic for benzene cycle conjugated with carbcation. ${ }^{18}$ These results suppose the earlier suggestion about formation of $\mathrm{Ni}(\mathrm{I})$ carbocationic complexes in the catalytic system which was done on the bases of UV spectroscopy data. ${ }^{19}$ So, 
the following scheme of styrene activation on cationic complex $\left[\mathrm{Ni}\left(\mathrm{PPh}_{3}\right)_{3}\right] \mathrm{BF}_{4}$ might be applied (Scheme 1.).

Unlike to the ethylene system, $\pi$-complex 2 was not found in the case of styrene which is connected with more rapid $\pi$ - $\sigma$-rearrangement.

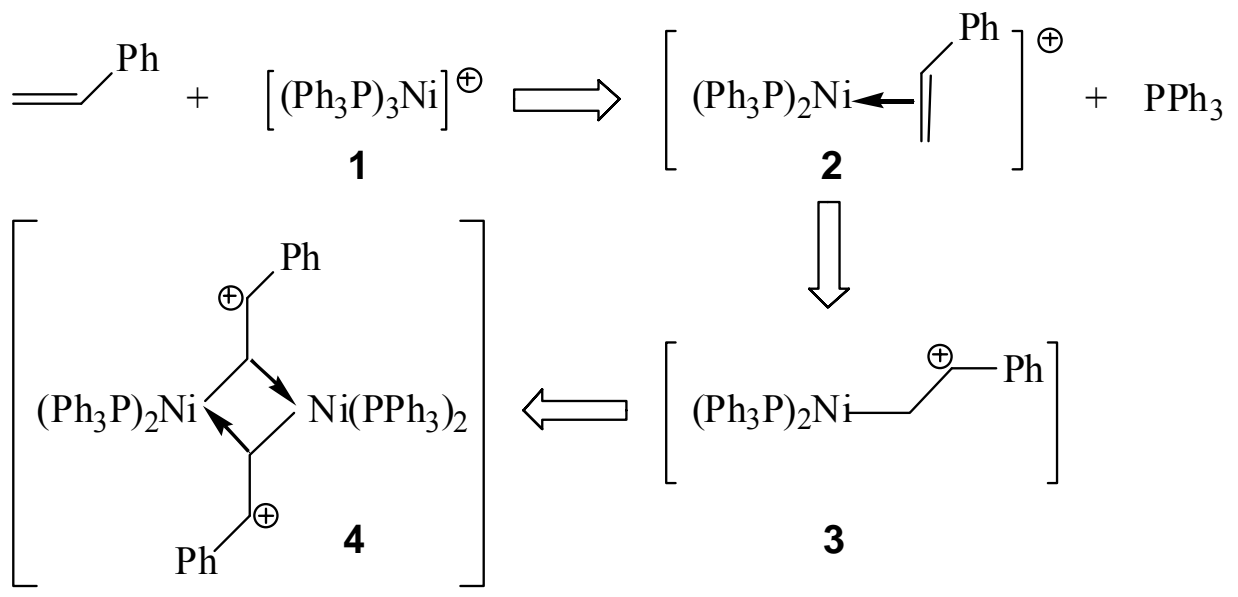

Scheme 1. Styrene activation on cationic complex.

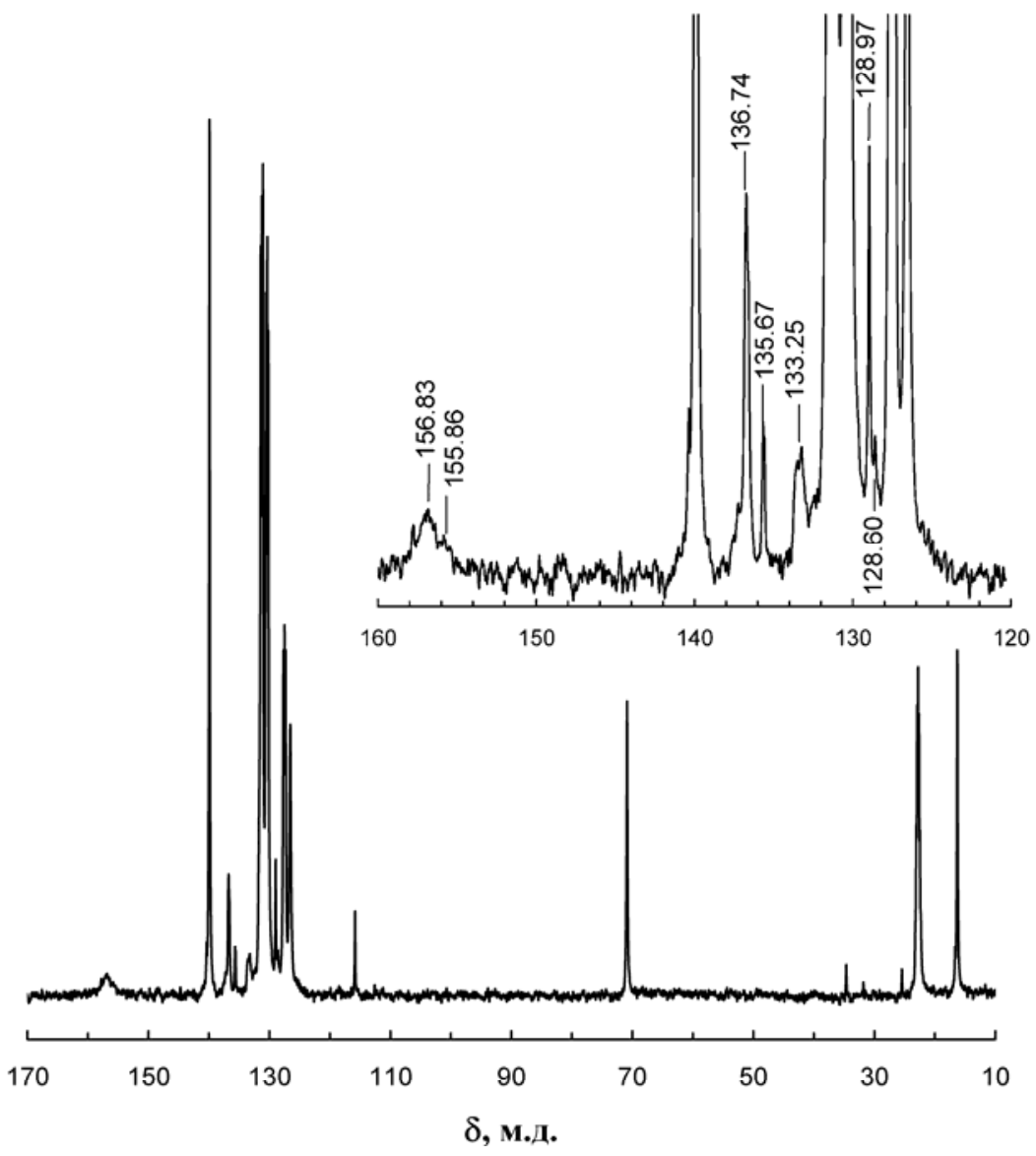

Figure 4. $\mathrm{NMR}{ }^{13} \mathrm{C}$ spectrum of $\mathrm{Ni}\left(\mathrm{PPh}_{3}\right)_{4} / \mathrm{BF}_{3} \cdot \mathrm{OEt}_{2} / \mathrm{C}_{8} \mathrm{H}_{8}$ system $\left(\mathrm{Ni}: \mathrm{B}: \mathrm{C}_{8} \mathrm{H}_{8}=1: 4: 2\right)$ in toluene- $\mathrm{d}_{8}$. 
The addition of styrene (styrene: $\mathrm{Ni}=200)$ to the catalytic system $\mathrm{Ni}\left(\mathrm{PPh}_{3}\right)_{4} / \mathrm{BF}_{3} \cdot \mathrm{OEt}_{2}(\mathrm{~B}: \mathrm{Ni}$ $=4)$ in which nickel exists as cationic complex $\left[\mathrm{Ni}\left(\mathrm{PPh}_{3}\right)_{3}\right] \mathrm{BF}_{4}$ results in styrene polymerization. The data from Figure 5 show an induction period before the active styrene conversion due to substitution of the phosphine ligand with styrene. The reaction proceeds up to full conversion of the monomer, but the polymer yield is $67 \%$ only, which points to the formation of low-molecular ethanol-soluble oligomers. The addition of new monomer portions to the reaction mixture after completion of the polymerization gives rise to resuming of the process, up to styrene $: \mathrm{Ni}=800$ at which ratio high viscosity of the system makes impossible the reaction. This points to relative stability of the carbocationic centers and correlates with the possibility to observe carbocations in NMR spectra. The obtained product is a paraffin-like material, it has band in FTIR spectrum at $1640 \mathrm{~cm}^{-1}$ which corresponds to the absorbance of double bonds. NMR ${ }^{13} \mathrm{C}$ spectra show signal at $137-138 \mathrm{ppm}$ pointing to terminal unsaturated moieties $\mathrm{CH}_{2}=\underline{\mathbf{C}}_{-}^{--}$, their contents is $1.5 \mathrm{~mol} . \%$ from the total styrene units. Molecular mass of the polymer is 2500 .

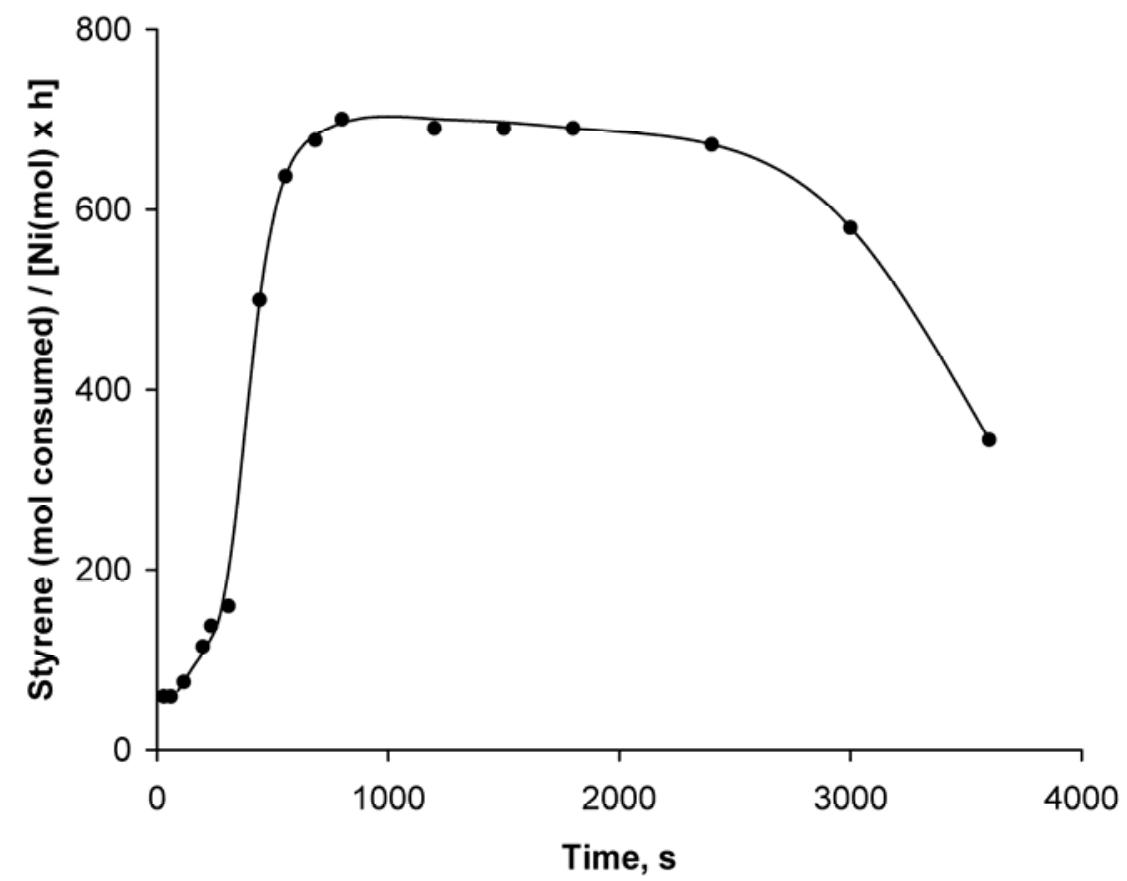

Figure 5. Time dependence of catalytic activity of $\mathrm{Ni}\left(\mathrm{PPh}_{3}\right)_{4} / \mathrm{BF}_{3} \cdot \mathrm{OEt}_{2}(\mathrm{~B}: \mathrm{Ni}=4)$ system in styrene polimerization, $20{ }^{\circ} \mathrm{C}$.

In the case of methylacrylate and methylmethacrylate the polymerization was not observed. The inactivity of monomers with an acceptor substituent at the double bond indicates mainly cationic nature of the active $\mathrm{Ni}$ complexes. On the other hand, addition of triethylamine as typical inhibitor of cationic polymerization results in $30 \%$ deceleration of the reaction only at the ration $\mathrm{NEt}_{3}: \mathrm{Ni}=5$. Similarly to ethylene, triethylphosphite completely suppresses the reaction 
giving rise to paramagnetic complex $\left[\left(\mathrm{PPh}_{3}\right) \mathrm{Ni}\left(\mathrm{P}(\mathrm{OEt})_{3}\right)_{3}\right] \mathrm{BF}_{4}$. Introduction of large amounts of ethanol into the system also terminates polymerization, and the signals of the ethoxy groups were found in ${ }^{13} \mathrm{C}$ NMR spectrum (74-83 and 64-68 ppm).

Results of this work and previous data ${ }^{19}$ allow us to propose the following scheme of the reactions of unsaturated hydrocarbons on $\mathrm{Ni}(\mathrm{I})$ cationic complexes (Scheme 2.).

Products of these reactions are unsaturated compounds useful as starting compounds for organic synthesis and polymer chemistry.

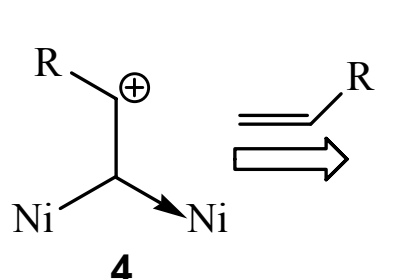

4

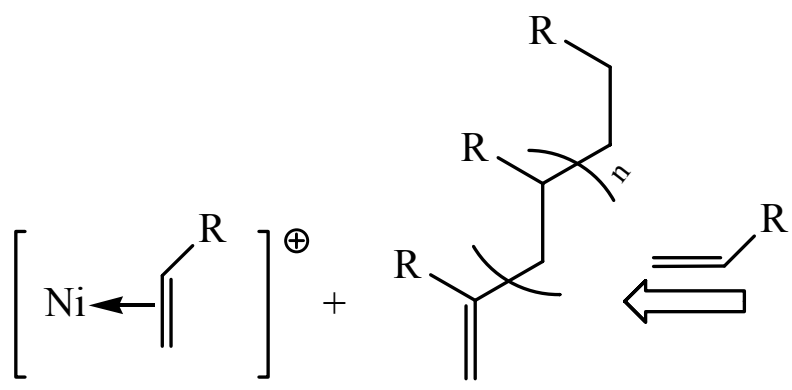

2

5<smiles>[R][CH][C@H]([N])NC=C[R]</smiles><smiles>C=CC</smiles>

$\mathrm{Ni}$<smiles>[R]CC=CCCC([R])CC([R])C([N])[N]</smiles>

9<smiles>[R]C[C@@H]([NH])C([R])C[NH]</smiles>

6

$\left\lceil\mathrm{HOR}^{\mathrm{I}}\right.$<smiles>[R]CCC(C)(CC([R])(C)C([R])([R])C)C([R])O</smiles><smiles>[R]CC(N)C([R])C[N]</smiles><smiles>C=CC</smiles><smiles>[R]CC[C+]([R])C([N])[N]</smiles>

8

Scheme 2. Transformations of unsaturated hydrocarbons on $\mathrm{Ni}(\mathrm{I})$ cationic complexes.

\section{Experimental Section}

General Procedures. All operations with nickel catalysts were carried out in purified agron by the Shlenk-technology. Glass Shlenk filters were used for filtration. All reagents were stored in argon-filled ampoules. Toluene, benzene and heptan (Merck) were distilled under sodium in the presence of benzophenone before use. Boron trifluoride etherate (Merck) was distilled under $\mathrm{LiH}$ 
in argon. Ethanol was dehydrated by distilling with sodium $(10 \mathrm{~g} / \mathrm{L})$. Diethyl ether was distilled under sodium and stored under sodium mirror. Styrene was distilled in vacuum $\left(32{ }^{\circ} \mathrm{C} / 10 \mathrm{~mm}\right.$ $\mathrm{Hg}$ ). The EPR spectra were run on a PS-100X instrument at $25^{\circ} \mathrm{C}$. Diphenylpicrylhydrazile and $\mathrm{Mn}^{2+}$ in $\mathrm{MgO}$ were used as the field standards. NMR spectra were recorded at $20{ }^{\circ} \mathrm{C}$ on a VXR500S "Varian" spectrometer. FTIR spectra were obtained on a Bruker IFS25 spectrometer ( $\mathrm{KBr}$ pellets). Molecular mass of the polystyrene sample was determined by isopiestic method using azobenzene as standard. ${ }^{20}$

Synthesis of $\left[\mathbf{N i}\left(\mathbf{P P h}_{3}\right)_{3}\right] \mathbf{B F}_{4}$ complex ${ }^{15} \cdot \mathrm{BF}_{3} \cdot \mathrm{OEt}_{2}(0.23 \mathrm{~mL})$ was added with a syringe upon stirring to a solution of $\mathrm{Ni}\left(\mathrm{PPh}_{3}\right)_{4}(0.5 \mathrm{~g}, \mathrm{~B}: \mathrm{Ni}=4: 1)$ in toluene $(10 \mathrm{ml})$ during $10 \mathrm{~min}$ at room temperature under argon. The mixture was cooled down to $-10{ }^{\circ} \mathrm{C}$ and precipitate was filtered off. $\left[\left(\mathrm{PPh}_{3}\right)_{3} \mathrm{Ni}\right] \mathrm{BF}_{4}$ complex was isolated from filtrate by precipitation with heptane as brown solid with 75\% yield (0.3 g). Found, \%: Ni 6.6, C 69.3; H 4.86; P 9.78. $\mathrm{C}_{54} \mathrm{H}_{45} \mathrm{P}_{3} \mathrm{NiBF}_{4}$. Calcd, \%: Ni 6.3; C 69.5; H 4.80; P 9.99.

Ethylene oligomerization. Toluene $(10 \mathrm{ml})$ and nickel complex $\left(10^{-4} \mathrm{~mol}\right)$ were placed into temperature-controlled reactor placed on a shaker at $20{ }^{\circ} \mathrm{C}$ and ethylene was bubbled through the solution of catalyst. Amount of the unreacted ethylene was measured volumetrically. The catalyst was destroyed by the addition of water after the reaction end, and the organic fraction was dried under calcium chloride; the oligomerization products were distilled off and analyzed by GLC on a "GALS" chromatograph equipped with flame-ionization detector and capillar column (15 m, HP-5).

Styrene polymerization. Toluene $(10 \mathrm{ml})$ and nickel complex $\left(10^{-4} \mathrm{~mol}\right)$ were placed into a temperature-controlled reactor at $20{ }^{\circ} \mathrm{C}$ and styrene was added under vigorous stirring. Unreacted styrene was monitored using GLC data obtained on a "GALS" chromatograph equipped with flame-ionization detector, phase: apieson, column length: $1500 \mathrm{~mm}$, diameter: $5 \mathrm{~mm}$. The resulting polymer was precipitated into ethanol and dried in vacuum.

\section{Acknowledgements}

The study was supported by the funds NWO (Netherlands) and RFBR (Russia) (international grant N 047.015.014) and the Ministry of Education of RF (program "Development of scientific potential in high education").

\section{References and footnotes}

1. Wilke, G. Angew. Chem. 1988, 100, 189.

2. Keim, W.; Schulz, R. P. J. Mol. Catal. 1994, 92, 21. 
3. Vogt, D.; Cornils, B.; Herrmann, W. A. Aqueous-Phase Organometallic Chemistry; WileyVCH: Weinheim, 1998; p 541.

4. Koppl, A.; Alt, H. G. J. Mol. Catal. 2000, 154, 45.

5. Preishuber-Pflugl, P.; Brookhart, M. Macromolecules 2002, 35, 6074.

6. Daugulis, O.; Brookhart, M. Organometallics 2002, 21, 5926.

7. Gibson, V.; Spitzmesser, S. Chem. Rev. 2003, 103, 283.

8. Jenkins, J.; Brookhart, M. A. Organometallics 2003, 22, 250.

9. Malinoski, J.; Brookhart, M. Organometallics 2003, 25, 5324.

10. Jenkins, J.; Brookhart, M. A. J. Am. Chem. Soc. 2004, 126, 5827.

11. Shmidt, F. K. Catalysis of hydrogenation and dimerization reactions with complexes of metals of the first transition row; Irkutsk State Univ., 1986; p 157.

12. Nomuro, K.; Ishino, M.; Hazama, M.; Suzukamo, G. J. Mol. Catal. 1997, 126, L93.

13. Nomuro, K.; Minamide, C.; Nagase, M.; Itagaki, M.; Suzukamo, G. J. Mol. Catal. 1999, $137,1$.

14. Hiroshi, S.; Hideto, T.; Kiyoshi, I. J. Mol. Catal. 1999, 144, 285.

15. Tkach, V. S.; Gruznykh, V. A.; Myagmarsuren, G.; Belykh, L. B.; Saraev, V. V.; Shmidt, F. K. Koordinatsionnaya Khimiya 1994, 20, 618.

16. Saraev, V. V. ; Kraikivskii, P. B.; Lazarev, P. G.; Tkach, P. G.; Shmidt, P. G. Rus. J. Coord. Chem. 1999, 25, 204.

17. Saraev, V. V.; Kraikivskii, V. V.; Lazarev, P. G.; Myagmarsuren, Gomboogiin; Tkach, V. S.; Shmidt, F. K. Rus. J. Coord. Chem. 1996, 22, 608.

18. Koptyug, V. A. Arenonic ions. Structure and reactivity; Nauka: Novosibirsk, 1983.

19. Saraev, V. V.; Kraikivskii, P. B.; Zelinskii, S. N.; Ratovskii, G. V.; Tkach, V. S.; Shmidt, F. K. Rus. J. Coord. Chem. 2001, 27, 757.

20. Rabek, J. F. Experimental methods in polymer chemistry; A Wiley-Interscience Publ., John Wiley \& Sons: Chichester-New York-Brisbane-Toronto, 1982; p 104. 